\title{
Adjustment of culture media to optimize in vitro rhizogenesis of domestic plums of various origins
}

\author{
Natalia Kovalenko ${ }^{l *}$, and Nadezhda Polivara $^{2}$ \\ ${ }^{1}$ Federal Research Center All-Russian Institute of Plant Genetic Resources named after N.I. Vavilov, \\ Crimean Experimental Breeding Station - branch of VIR, st. Vavilova, 12, Krasnodar region, Krymsk, \\ 353384, Russia \\ ${ }^{2}$ Krymsk Experiment Breeding Station of VIR, N.I. Vavilov All-Russian Institute of Plant Genetic \\ Resources, Krymsk, Krasnodar Region, 353384, Russia
}

\begin{abstract}
This paper presents the results of the adjustment of 18 modifications of culture medium based on MS medium composition Murashige and Skoog (1962) for in vitro rhizogenesis of 10 varieties of domestic plum. There were used 4 nutrient media with a full amount of macro- and microelements - $\mathrm{MS}_{1}$ with a different combination of phytohormones, 1 medium without hormones $-\mathrm{MS} c, 13$ media $-\mathrm{MS}_{2}$ with half the amount of macronutrients, differing in hormonal composition. It was found that the maximum number of rooted microshoots from 21.2 to $52.2 \%$ was on $\mathrm{MS}_{2-8}$ medium, from 11.2 to $43.1 \%$ on $\mathrm{MS}_{2-5}$. The analysis showed that into the medium increases the percentage of microplants by $12-17 \%$ comparing with the medium $\mathrm{MS}_{2-5}$ and $\mathrm{MS}_{2-7}$ without FA. The distinctiveness of nutrient media by the type of auxin (IAA, NAA, IBA) made it possible to clarify that IBA is the most optimal of the auxins, and the concentration of $1.7 \mathrm{mg} / \mathrm{l}$ is borderline for the growth reactions of plum varieties. It was revealed that in vitro root formation depends not only on the compositions of growth substances in the nutrient medium, but also on the genotype of the variety.
\end{abstract}

\section{Introduction}

Industrial plantings of domestic plum (Prunus domestica L. subsp. Domestica Mansfeld) are high-cost agrocenoses, and for their quickest payback and consistently high profitability throughout the entire exploitation, it is necessary to have competitive varieties $[1,2]$. In the North Caucasus, such an assortment has already been determined that meets the requirements of producers and consumers of plum fruits. These are varieties of domestic and foreign selection: Stanley, Blue Dream, Blue Free, Autumn Souvenir, Kabardinskaya Early, Big Prize, Ballad, Debut, Prestige, and Empress.

To carry out at the modern level the establishment of both scion and collection plantings of domestic plum varieties, it is necessary to involve biotechnological methods, one of which is micropropagation [3, 4]. In addition, a higher multiplication factor and obtaining a homogeneous material from individual representatives of the variety selected by the nursery 
breeder are possible, which most fully correspond to its phenotype, but also free from viral infection $[2,3,5,6]$.

More than 20 diseases of viral and phytoplasmic etiology circulate in fruit plantations of stone fruit crops [3]. Among the most harmful diseases of plum sharka (smallpox) (PPV) Plum pox potyvirus is and now has become a limiting factor in the cultivation of plum fruits due to their premature abscission or deterioration in quality, leading to yield losses of up to $85-100 \%[5,6]$

Due to the fact that the domestic plum is a hexaploid, cultigenic species, it is necessary to take this feature into account when working with it in an in vitro culture, selecting for each stage of subcultivation, an individual set of components of the nutrient medium. Over the past decade, in the literature, there are data concerning the experiments on the culture of isolated tissues of certain varieties of plum [4, 7-11].

The rooting stage is crucial and precedes the adaptation process. Higher efficiency of rhizogenesis of plum varieties on a nutrient artificial medium - MS - Murashige and Skoog (1962), as indicated by the authors working in this direction, there is a need to adjust it taking into account varietal characteristics [5, 7-9]. For example, a two-fold diluted MS nutrient medium is proposed $[12,13]$. The composition of the nutrient medium for reproduction and rhizogenesis can include substances of auxin nature with different concentrations [7, 14, 15]. Most of the work on the cultivation of domestic plums was carried out on two to five varieties, while using a small number of modifications of nutrient media, but emphasizing the need for individual selection of its components [3, 4, 7, 11-15].

The purpose of this work is to adjust the nutrient media at the stage of in vitro rooting for varieties of domestic plums of various genetic origin, which are in demand and are promising for cultivation by producers of the fruits of this crop in the Krasnodar Region.

The relevance of the work is based on the fact that the assessment of varieties of domestic plum for the ability to rooting in vitro and taking into account their characteristics was carried out, and the optimal composition for rhizogenesis of each and the most acceptable for most of them was determined.

\section{Materials and methods}

The studies were carried out in the laboratory of biotechnology and biochemistry of the Crimean experimental selection station of the VIR branch in the period from 2019 to 2021.

The study included varieties of domestic plum, available in the collection of the Crimean EBS. Information about their origin, indicating the numbers of the VIR catalog, is given in the "Catalog of promising varieties of fruit and berry crops isolated from the VIR collection" (2018).

The objects of this study were microshoots of 10 plum varieties with one or two "nodes" from one to one and a half centimeters high, isolated from conglomerates of a test tube culture at the stage of micropropagation for the stage of rhizogenesis.

The work was carried out according to the methodology developed by N.I. Medvedeva, V.N. Podorozhny, N.N. Kovalenko "Clonal micropropagation of stone fruit crops and their clonal rootstocks" (2014). For the preparation of nutrient media, inorganic salts of domestic and foreign production of the chemically pure grade were used. The culture media were autoclaved in a vertical autoclave VK-75 at the temperature of $+120^{\circ} \mathrm{C}$ and an operating pressure of $1 \mathrm{~atm}$. within 25 minutes. All work requiring aseptic conditions was carried out in a laminar box VL-12. Experimental nutrient media - 18, based on MS medium. These are three basic media in terms of mineral and vitamin composition: $\mathrm{MS}_{1}$ - complete composition, without meso-inositol, $\mathrm{MS}_{2}-1 / 2$ part of the macrosalt composition, without meso-inositol, and control MSc, where all the components according to the MS prescription were present. 
Microshoots were cultivated on the above modifications of the MS nutrient medium in test tubes $21 \times 135 \mathrm{~mm}$ under the conditions of a light hall. At the same time, the air temperature was constant $24 \pm 1{ }^{\circ} \mathrm{C}$, illumination 2.5-3.0 thousand lux, photoperiod 168 hours. In each variant of the experiment, at least 20 explants were analyzed, the experiment was repeated 3 times.

The assessment of the development of the root system was carried out every five days; the date and number of rooted microshoots were recorded. After two months, microshoots without roots were culled.

\section{Results and discussions}

Domestic plum has a number of features of the biology and genetics of varieties, which were taken into account when conducting these studies. In their pedigrees, the plum varieties included in the experiments have some regularity in origin: Stanley and varieties with his participation - Blue Dream, Blue Free, Autumn Souvenir; Kabardinskaya Early and varieties - Big Prize, Ballada, Debut, as well as a variety with the participation of Renklode Altana Prestige. It should be noted that Ballad, in its origin, has genes, like Hungarian, as well as Stanley. The experiments included culture media based on the Murashige and Skoog medium - MS, both the generally recognized MSc - taken as control, and a number of others (Table $1)$.

Table 1. Hormonal composition of basic nutrient media at the stage of in vitro rooting of domestic plums

\begin{tabular}{|c|c|c|}
\hline \multicolumn{3}{|c|}{ Nutrient medium } \\
\hline basic & modification & hormonal composition, $\mathrm{mg} / \mathrm{l}$ \\
\hline \multirow[t]{4}{*}{$\mathrm{MS}_{1}$} & $\mathrm{MS}_{1-1}$ & $\beta-$ IAA -1.5 \\
\hline & $\mathrm{MS}_{1-2}$ & IBA -1.5 \\
\hline & $\mathrm{MS}_{1-3}$ & IBA -1.8 \\
\hline & $\mathrm{MS}_{1-4}$ & $\mathrm{IBA}-2.0 ; \alpha-\mathrm{NAA}-0.2$ \\
\hline \multirow[t]{13}{*}{$\mathrm{MS}_{2}$} & $\mathrm{MS}_{2-1}$ & $\beta-$ IAA -1.0 \\
\hline & $\mathrm{MS}_{2-2}$ & $\beta-$ IAA -1.5 \\
\hline & $\mathrm{MS}_{2-3}$ & IBA $-0.5 ; \beta$ IAA -0.5 \\
\hline & $\mathrm{MS}_{2-4}$ & IBA -1.0 \\
\hline & $\mathrm{MS}_{2-5}$ & IBA -1.2 \\
\hline & $\mathrm{MS}_{2-6}$ & IBA -1.5 \\
\hline & $\mathrm{MS}_{2-7}$ & IBA $-1.5 ; \mathrm{GA}-0.5 ; 6-\mathrm{BAP}-0.001$ \\
\hline & $\mathrm{MS}_{2-8}$ & IBA $-1.5 ; \mathrm{GA}-0.5 ; 6-\mathrm{BAP}-0.001 ; \mathrm{FA}-1.0$ \\
\hline & $\mathrm{MS}_{2-9}$ & IBA -1.7 \\
\hline & $\mathrm{MS}_{2-10}$ & IBA - 2.0; GA - 0.5; 6-BAP - 0.001 \\
\hline & $\mathrm{MS}_{2-11}$ & IBA - 2.0; GA - 1.0; 6-BAP - 0.001 \\
\hline & $\mathrm{MS}_{2-12}$ & IBA - 2.2; GA - 1.0; 6-BAP - 0.001 \\
\hline & $\mathrm{MS}_{2-13}$ & IBA $-2.5 ; \mathrm{GA}-0.7 ; \mathrm{FA}-0.7$ \\
\hline $\mathrm{MS}_{\mathrm{C}}$ & $\mathrm{MS}_{\mathrm{C}}$ & without hormones \\
\hline \\
\hline $\begin{array}{l}\beta-\text { IAA } \\
\text { IBA } \\
\alpha-\text { NAA }\end{array}$ & $\begin{array}{l}-\beta \text { - indolylacetic acid; } \\
\text { - indolylbutyric acid; } \\
\text { - } \alpha \text { - naphthylacetic acid; }\end{array}$ & $\begin{array}{ll}\text { GA } & \text { - gibberellic acid; } \\
\text { 6-BAP } & -6 \text { benzylaminopurine; } \\
\text { FA } & - \text { ferulic acid. }\end{array}$ \\
\hline
\end{tabular}

The results of the experiments are presented in table 2. 
Table 2. Influence of the hormonal composition of the nutrient medium on the number of rooted microshoots of domestic plum

\begin{tabular}{|c|c|c|c|c|c|c|c|c|c|c|}
\hline $\begin{array}{l}\text { Modifi } \\
\text { cation } \\
\text { of MS }\end{array}$ & 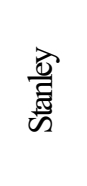 & 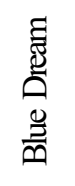 & 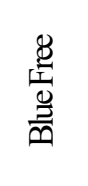 & 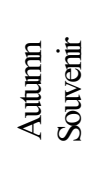 & 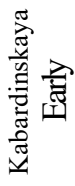 & 茴 & $\frac{\overrightarrow{\widetilde{Z}}}{\overline{\bar{\Xi}}}$ & $\begin{array}{l}\overrightarrow{0} \\
\stackrel{0}{0} \\
0\end{array}$ & 苞 & 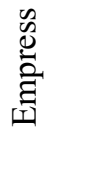 \\
\hline \multicolumn{11}{|c|}{ number of rooted micro-shoots, $\%$} \\
\hline $\mathrm{MS}_{1-1} *$ & 0 & 0 & 0 & 0 & 0 & 0 & 2.5 & 0 & 0 & 7.6 \\
\hline $\mathrm{MS}_{1-2}$ & 2.9 & 0 & 0 & 0 & 0 & 2.8 & 0 & 0 & 2.9 & 0 \\
\hline $\mathrm{MS}_{1-3}$ & 10.0 & 0.5 & 32.0 & 20.0 & 0 & 0 & 0 & 0 & 0 & 5.5 \\
\hline $\mathrm{MS}_{1-4}$ & 8.3 & 1.0 & 27.7 & 37.5 & 0 & 0 & 0 & 0 & 0 & 0 \\
\hline $\mathrm{MS}_{\mathrm{C}}$ & 0 & 0 & 0 & 0 & 0 & 0 & 0 & 0 & 0 & 0 \\
\hline $\mathrm{MS}_{2-1} *$ & 5.8 & 0 & 11.7 & 5.8 & 0 & 0 & 4.1 & 0 & 0 & 0 \\
\hline $\mathrm{MS}_{2-2}$ & 10.0 & 0 & 16.6 & 0 & 0 & 0 & 0 & 0 & 0 & 7.6 \\
\hline $\mathrm{MS}_{2-3}$ & 22.7 & 2.5 & 0 & 22.7 & 0 & 0 & 0 & 0 & 0 & 25.0 \\
\hline $\mathrm{MS}_{2-4}$ & $\begin{array}{c}52.2 \\
* *\end{array}$ & 30.7 & 0 & $\begin{array}{c}42.1 \\
* *\end{array}$ & 9.0 & 9.6 & 33.3 & 7.6 & 5.5 & 15.3 \\
\hline $\mathrm{MS}_{2-5}$ & 39.2 & $\begin{array}{c}39.2 \\
* *\end{array}$ & $\begin{array}{c}40.0 \\
* *\end{array}$ & 36.3 & 11.2 & $\begin{array}{c}43.1 \\
* *\end{array}$ & 33.3 & 16.6 & 20.0 & 33.3 \\
\hline $\mathrm{MS}_{2-6}$ & 29.1 & 29.1 & 17.8 & 17.8 & 16.6 & 15.3 & 20.0 & 20.0 & 26.6 & 25.0 \\
\hline $\mathrm{MS}_{2-7}$ & 25.4 & 17.4 & 28.2 & 25.4 & 9.0 & 6.3 & 25.5 & 26.6 & 35.0 & 16.8 \\
\hline $\mathrm{MS}_{2-8}$ & 36.1 & 38.4 & 36.6 & 36.1 & $\begin{array}{c}21.2 \\
* *\end{array}$ & 20.9 & $\begin{array}{c}52.2 \\
* *\end{array}$ & $\begin{array}{c}28.5 \\
* *\end{array}$ & $\begin{array}{c}43.0 \\
* *\end{array}$ & $\begin{array}{c}43.4 \\
* *\end{array}$ \\
\hline $\mathrm{MS}_{2-9}$ & 28.1 & 18.1 & 29.0 & 17.6 & 10.0 & 17.5 & 0 & 5.5 & 6.6 & 0 \\
\hline $\mathrm{MS}_{2-10}$ & 17.6 & 2.8 & 0.2 & 24.4 & 0 & 0 & 0 & 0 & 0 & 0 \\
\hline $\mathrm{MS}_{2-11}$ & 19.7 & 19.7 & 37.8 & 33.3 & 0 & 0 & 11.1 & 0 & 0 & 12.0 \\
\hline $\mathrm{MS}_{2-12}$ & 0 & 0 & 0 & 27.2 & 0 & 0 & 0 & 0 & 0 & 20.0 \\
\hline $\mathrm{MS}_{2-13}$ & 0 & 0 & 0 & 0 & 0 & 0 & 0 & 0 & 0 & 0 \\
\hline
\end{tabular}

Note: ${ }^{*}$ - the composition of nutrient media, see table. $1 ;{ }^{* *}$ - maximum number of rooted shoots

The most optimal nutrient medium for most varieties of plum is $\mathrm{MS}_{2-8}$ with half the content of macronutrients from the composition according to the MS prescription and the following phytohormones in an amount: IBA - $1.5 \mathrm{mg} / \mathrm{l}, \mathrm{GA}-0.5 \mathrm{mg} / 1,6-\mathrm{BAP}-0.001 \mathrm{mg} / \mathrm{l}$, FA - $1.0 \mathrm{mg} / \mathrm{l}$. At the same time, roots were formed in all varieties in the range from $20.9 \%$ (Big Prize) to $52.2 \%$ (Ballad), and on average, about $40 \%$. It should be noted that FA ferulic or hydroxycinnamic acid - is an oxidant that enhances the effect of vitamin $\mathrm{C}$ and helps to restore plant cell membranes. It was taken into account that such a combination, presumably, has antimutagenic qualities, which is important when cultivating varieties in vitro. It was also introduced into the $\mathrm{MS}_{2-13}$ medium $(0.7 \mathrm{mg} / \mathrm{l})$, but at higher IBA values $2.5 \mathrm{mg} / \mathrm{l}$ and GA - $0.7 \mathrm{mg} / \mathrm{l}$, however, this combination of hormones did not show a positive effect: roots were not formed in all varieties, without exception, as when using the control medium - $\mathrm{MS}_{\mathrm{C}}$ - without hormones.

The combination of IBA and $\beta$-IAA at $0.5 \mathrm{mg} / 1$ in $\mathrm{MS}_{2-3}$ medium, as well as IAA concentrations of 1.0 and $1.5 \mathrm{mg} / \mathrm{l}$ in MS2-1 and $\mathrm{MC}_{2-2}$ media, adversely affect the process of root formation, as well as increased concentrations of IBA - $2.2 \mathrm{mg} / \mathrm{l}$ in $\mathrm{MS}_{2-12}$ medium. The limiting concentration in the nutrient medium for rhizogenesis of most plum varieties is obviously $1.7 \mathrm{mg} / 1$, as in the $\mathrm{MS}_{2-9}$ medium. A decrease in the content of IBA to 1.0 and 1.2 $\mathrm{mg} / \mathrm{l}$ (without GA) in the $\mathrm{MS}_{2-4}$ and $\mathrm{MS}_{2-5}$ media promoted the rhizogenesis of only certain 
varieties. So, on the $\mathrm{MS}_{2-4}$ nutrient medium, good root formation was noted in the varieties Stenley - 52.2\%, Blue Dream - 30.7\%, Autumn Souvenir - 42.1\%, Ballada - 33.3\%, in comparison with others: Kabardinskaya Early, Big Prize, Debut, Prestige and Empress - 9.0; $9.6 ; 7.6 ; 5.5 ; 15.3$ respectively. These data show that there is a dependence of the ability for in vitro rhizogenesis on the genotype of plum varieties.

Figure 1 shows rooted microshoots of domestic plum varieties grown on $\mathrm{MS}_{2}$ nutrient media before ex vitro planting.

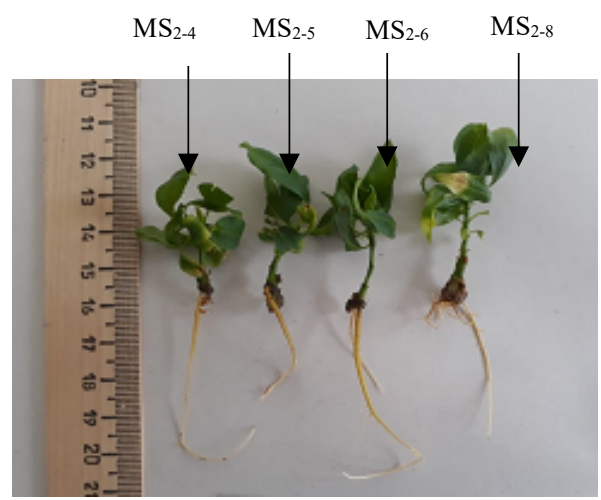

a)

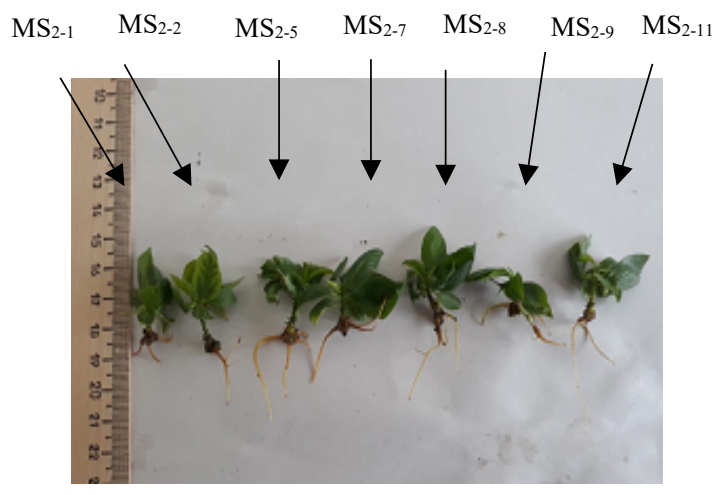

b)

Fig. 1. Rooted microshoots of domestic plum varieties grown on MC2 nutrient media before ex vitro planting a) Blue Dream, b) Blue Free

\section{Conclusion}

As a result of the research, it was revealed that in vitro root formation of domestic plum varieties depends on the composition of the nutrient medium, both mineral and hormonal. When analyzing the obtained data of rhizogenesis of 10 plum varieties on 18 medium variants based on the composition of the nutrient medium Murashige and Skoog (1962), it was determined that the maximum number of rooted microshoots (from 21.2 to $52.2 \%$ ) was on $\mathrm{MS}_{2-8}$ medium. and slightly lower (from 11.2 to $43.1 \%$ ) - on $\mathrm{MS}_{2-5}$.

It was found that addition of FA to the $\mathrm{MS}_{2-8}$ medium increased the percentage of microplants yield on average by $12 \%$ in comparison with the $\mathrm{MS}_{2-5}$ medium and by $17 \%$ $\mathrm{MS}_{2-7}$ (without FA).

Correction of nutrient media at the stage of in vitro rooting of plums was made taking into account the mineral composition of salts: $\mathrm{MS}_{1}$ - full composition in four modifications, $\mathrm{MS}_{2}-1 / 2$ composition in 13 modifications and $\mathrm{MS}_{\mathrm{c}}$ - full composition, without hormones. Modifications in the composition of hormones varied, but in general, they can be divided into distinctness by the type of auxin (IAA, NAA, and IBA) and its concentration. Experiments have shown that rhizogenesis of plum cultivars occurs optimally in the presence of IBA at a concentration up to $1.7 \mathrm{mg} / \mathrm{l}$. $\mathrm{MS}_{1}$ nutrient media are unsuitable for plum rhizogenesis, varieties on them showed low results and only in some: Stenley, Blue Free, Autumn Souvenir - rooted microshoots were from 10.0 to $37.5 \%$ on $\mathrm{MS}_{1-3}$ medium.

It was revealed that in vitro root formation also depends on the genotype of the variety: Stanley and varieties with its participation in the origin - Blue Dream, Blue Free, Autumn Souvenir are more capable of active development in comparison with others. The results of the study are the basis for further research with the aim of increasing the yield of rooted microshoots and developing a method for clonal micropropagation of domestic plum varieties. 
Acknowledgments. The work was performed on the VIR collection of plant genetic resources within the framework of the state assignment in accordance with the VIR thematic plan for project No. 06622019-0004 "Collections of vegetatively propagated crops (potatoes, fruit, berry, ornamental, grapes) and their wild relatives VIR - study and rational use ".

\section{References}

1 B.L. Topp, D.M. Russell, M. Neumuller, M.A. Dalbo, W. Liu, Plum, In: M.L. Badenes, D.H. Byrne (edd.) Fruit Breeding, 571-621 (Springer, Boston, MA., 2012) https://doi.org/10.1007/978-1-4419-0763-9 15

2 K. Gurcan, A. Ceylan, Turk. J. Agric. Forest., 40, 746-760 (2016) http://doi.org/10.3906/tar-1509-97

3 A.A. Batukaev, I.M. Bamatov, M.A. Vinter, J. Pharm. Sci. Res., 10(1), 59-64 (2018) https://www.researchgate.net/publication/322939881

4 J.M. Bandeira, C.P. Silva, L.B. Thurow, E.J.B. Braga, J.A. Peters, V.J. Bianchi, Revista de la Facultad de Agronomía, La Plata, 112 (1), 44-50 (2013) http://revista.agro.unlp.edu.ar/index.php/revagro/article/view/55

5 J. Sochor, P. Babula, V. Adam, B. Krska, R. Kizek, Viruses, 4(11), 2853-2901 (2012) https://doi.org/10.3390/v4112853

6 Zs. Jakab-llyefalvi, D. Pamfil, Ann. of Rom. Soc. Cell Bio., XVI(1), 55-61 (2011) https://www.researchgate.net/publication/261638768

7 E. Kassaye, J. Biotech Res., 8(1), 18-26 https://www.researchgate.net/publication/316938937

8 O. Ostadsharif, G. Garoosi, R. Haddad, and E. Nezami, Agric. Biotech., 13(1), 3-5 (2014) http://www.ikiu.ac.ir/public-files/profiles/items/090ad_1435487423.pdf

9 M. Fallahpour, S.M. Miri, N. Bouzari, J. Hortic. Res., 23(1), 57-64 (2015) https://doi.org/10.2478/johr-2015-0008

10 Y.N. Zou, Not. Bot. Horti Agrobor. Cluj, 38(3), 214-218 (2010) https://doi.org/10.15835/nbha3834614

11 F. Sadeghi, A. Yadollahi, M. Jafarkhani Kermani, M. Eftekhari, J. Gen. Eng. Biotech., 13,19-23 (2015) https://doi.org/10.1016/j.jgeb.2014.12.006

12 J. Alam. R. Barua, J. BioSci. Biotech., 4(1), 9-15 (2015) https://www.researchgate.net/publication/281457185

13 A. Barbulescu, M. Neamtu, A. Ilie, and A. Petcu, G. Popa, Acta Hortic., 814(814), 227 230 (2009) https://10.17660/ActaHortic.2009.814.31

14 E.K. Wolella, B. Dagnaw, Int. J. Bio-Tech. Res., 7(2), 17-28 (2017) http://paper.researchbib.com/view/paper/128442

15 R.A. Ranyaphi, A. A. Mao, S.K. Borthakur, Ind. J. Biotech., 11(2) 197-204 (2012) https://www.researchgate.net/publication/287720592 